\title{
Genetic analysis of African swine fever virus based on major genes encoding p72, p54 and p30
}

\author{
Hop Q. Nguyen ${ }^{1}$, Duyen M. T. Nguyen ${ }^{1}$, Nam M. Nguyen ${ }^{2}$, Dung N. T. Nguyen ${ }^{1}$, \\ Han Q. T. Luu ${ }^{1}$, \& Duy T. Do ${ }^{1 *}$ \\ ${ }^{1}$ Faculty of Animal Science and Veterinary Medicine, Nong Lam University, Ho Chi Minh City, Vietnam \\ ${ }^{2}$ Research Center for Genetics and Reproductive Health, School of Medicine, Vietnam National University, \\ Ho Chi Minh City, Vietnam
}

\section{ARTICLE INFO}

Research Paper

Received: April 24, 2021

Revised: June 01, 2021

Accepted: June 08, 2021

Keywords

ASFV

Genotyping

p30

p5 54

p72

\section{${ }^{*}$ Corresponding author}

Do Tien Duy

Email: duy.dotien@hcmuaf.edu.vn

\begin{abstract}
African swine fever (ASF) is reported as a highly contagious hemorrhage lethal disease of domestic and wild swine. The causative agent of ASF is a large enveloped DNA virus with a complex structure. There are twenty-four ASFV genotypes described to date. However, in Vietnam, only genotypes II had been previously described. The genetic characterization of ASFV enhances the understanding of ASF epidemiology in terms of the extent, severity, source, and potential genetic variations among ASFV strains circulating in Southern Vietnam. Twenty ASFV strains were collected from pigs with ASFV-infected clinical signs from 10 provinces during 2019 2020. Partial B646L (p72) gene, complete E183L (p54), and CP204L (p30) genes were amplified, purified, and sequenced. Phylogenetic analysis confirmed the circulation of genotype II by both the partial B646L (p72) and full-length E183 (p54) gene sequencing. Analysis of the p72, p54, and p30 regions did not indicate any change in the nucleotide and amino acid sequences among these strains. The results of this study revealed that these ASFVs shared high homology to ASFV isolates detected in Northern Vietnam and China.
\end{abstract}

Cited as: Nguyen, H. Q., Nguyen, D. M. T., Nguyen, N. M., Nguyen, D. N. T., Luu, H. Q. T., \& Do, D. T. (2021). Genetic analysis of African swine fever virus based on major genes encoding p72, p54 and p30. The Journal of Agriculture and Development 20(3), 18-25.

\section{Introduction}

African swine fever (ASF) is reported as a highly contagious hemorrhage lethal disease by the World Organization for Animal Health (OIE, 2019). First described in Kenya in 1921, it happened on the African continent until 1957, when it spread from Angola to Lisbon. From then on, African swine fever virus (ASFV) has been repeatedly identified in many countries of Europe, Central America, and South America. The introduction of ASFV into Georgia from Southeast Africa in 2007 was described by Rowlands (2008). After that, ASFV crossed into the Eastern European Union (EU) territory in 2014 and affected
Lithuania, Poland, Latvia, and Estonia in 2014, the Czech Republic and Romania in 2017, and Hungary and Bulgaria in 2018 (Gallardo et al., 2017; OIE, 2018). In 2018, the disease reached China having the largest pig production (Ge et al., 2018), followed by Vietnam (2019) (Le et al., 2019), and other Asian countries, which caused the devastation of pig industry, leading to substantial economic loss due to the lack of an effective vaccine (FAO, 2020).

African swine fever is caused by the ASFV that is the only member of the family ASFarviridae (Dixon et al., 2020). ASFV was classified into 24 genotypes (Quembo et al., 2018). The different strains lead to variable pathogenesis ranging 
from highly lethal to asymptomatic. The highly virulent genotype II is confirmed as a circulating strain in China, and Vietnam which showed high mortality (91-100\%), making ASF the most severe restriction on domestic pig production, food security, and livelihood and socioeconomic effects (Ge et al., 2018; Gallardo et al., 2019).

In Vietnam, the previously characterized ASFV have been reported only genotype II based on sequencing of the C-terminal region of the B646L gene (Le et al., 2019; Tran et al., 2020; Mai et al., 2021). Further differentiation between close strains and identifying virus subtypes of the 24 genotypes was achieved by nucleotide sequencing of the whole E183L gene regions encoding p54 proteins and the CP204L gene encoding the phosphoprotein $\mathrm{p} 30$. Previous studies have shown that using the three encoding regions of the ASFV DNA including p72, p54, and p30, to characterize ASFV is much sufficient despite the presence of many other markers (Nix et al., 2006; Gallardo et al., 2009).

This study was set out to characterize African swine fever virus genotypes from 20 farms in 10 provinces, which occurred ASF outbreaks in 2019 and 2020. The results are expected to contribute sequence data for molecular epidemiology studies and provide further understanding of ASF disease patterns in Southern Vietnam.

\section{Materials and Methods}

\subsection{Study design and sample collection}

This study was conducted in 10 Southern provinces of Vietnam (Figure 1). Samples were collected from clinical pigs in ASF outbreaks reported in the period of 2019 - 2020. Sets of lymph nodes, spleens, kidney, lung, and whole blood from 20 pigs were collected for diagnosis according to the OIE-recommendation, then the whole blood used for DNA extraction submitted to sequencing. PCR amplification of ASFV detection was performed using primers PPA-1/PPA-2 described in previous studies (Table 1). Sample source, temporal and spatial distribution of specimens were summarized in Table 2.

\subsection{DNA extraction and PCR assay}

The genomic DNA of ASFV was extracted following the manufacturer's instructions of the commercial kit Promega ${ }^{\mathrm{TM}}$ Wizard $^{\mathrm{TM}} \mathrm{SV}$ 


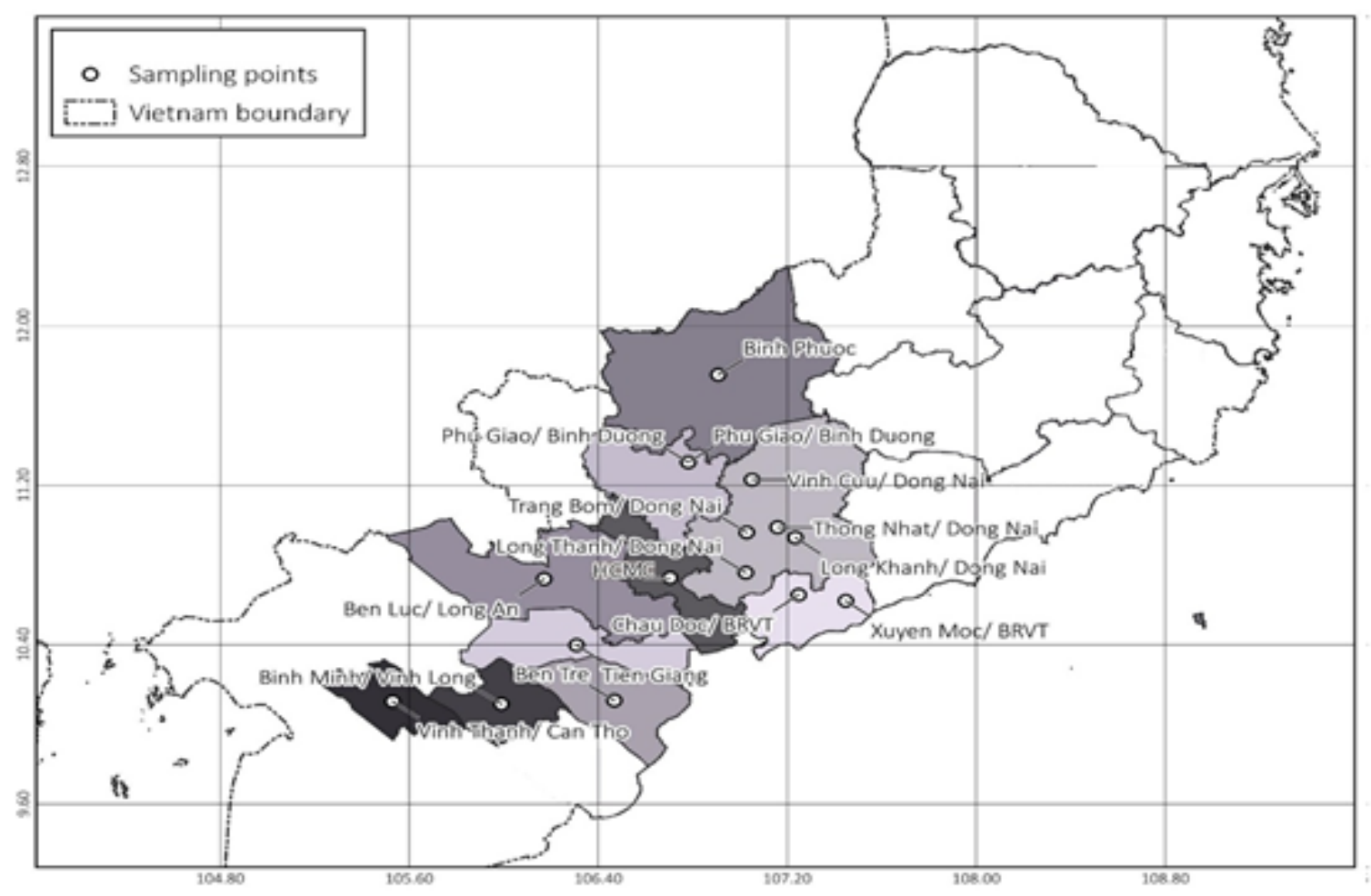

Figure 1. Map of Vietnam showing locations where field strains were obtained and genotyped.

Table 2. Summary of African swine fever viruses used in this study

\begin{tabular}{|c|c|c|c|c|}
\hline ASFV strains & District/province & Sampling date & $\begin{array}{lr}\begin{array}{lr}\text { Sample } \\
\text { tained }\end{array} & \text { ob- } \\
\text { each pig } & \\
\end{array}$ & Host \\
\hline VN/HCMC/2019-ASF1 & Binh Tan/HCMC & July, 2019 & $\mathrm{~S}$ & $\mathrm{DP}$ \\
\hline VN/BRVT/2019-ASF1 & Chau Doc/BRVT & August, 2019 & S & DP \\
\hline VN/BRVT/2019-ASF2 & Xuyen Moc/BRVT & November, 2019 & S & DP \\
\hline VN/BD/2019-ASF1 & Phu Giao/Binh Duong & September, 2019 & $\mathrm{~S}, \mathrm{Sp}, \mathrm{K}, \mathrm{L}, \mathrm{LN}$ & DP \\
\hline $\mathrm{VN} / \mathrm{BD} / 2019-\mathrm{ASF} 2$ & Phu Giao/Binh Duong & July, 2019 & $\mathrm{~S}, \mathrm{Sp}, \mathrm{K}, \mathrm{L}, \mathrm{LN}$ & $\mathrm{CP}$ \\
\hline $\mathrm{VN} / \mathrm{BD} / 2020-\mathrm{ASF} 3$ & Phu Giao/Binh Duong & July, 2020 & $\mathrm{~S}$ & DP \\
\hline $\mathrm{VN} / \mathrm{BD} / 2020-\mathrm{ASF} 4$ & Phu Giao/Binh Duong & June, 2020 & S & $\mathrm{CP}$ \\
\hline VN/BP/2019-ASF1 & Binh Phuoc & June, 2019 & S & DP \\
\hline VN/DN/2019-ASF1 & Trang Bom/Dong Nai & June, 2020 & $\mathrm{~S}$ & $\mathrm{CP}$ \\
\hline VN/DN/2019-ASF2 & Vinh Cuu/Dong Nai & June, 2019 & $\mathrm{~S}$ & DP \\
\hline VN/DN/2019-ASF3 & Long Thanh/Dong Nai & August, 2019 & S & DP \\
\hline $\mathrm{VN} / \mathrm{DN} / 2020-\mathrm{ASF} 4$ & Long Khanh/Dong Nai & May, 2020 & $\mathrm{~S}$ & $\mathrm{CP}$ \\
\hline VN/DN/2020-ASF5 & Thong Nhat/Dong Nai & July, 2020 & S & DP \\
\hline VN/BenTre/2020-ASF1 & Ben Tre & December, 2020 & WB & DP \\
\hline VN/CT/2019-ASF1 & Vinh Thanh/Can Tho & July, 2019 & S & DP \\
\hline VN/LA/2019-ASF1 & Ben Luc/Long An & September, 2019 & $\mathrm{~S}, \mathrm{Sp}, \mathrm{K}, \mathrm{L}, \mathrm{LN}$ & DP \\
\hline VN/LA/2019-ASF2 & Ben Luc/Long An & October, 2019 & $\mathrm{~S}, \mathrm{Sp}, \mathrm{K}, \mathrm{L}, \mathrm{LN}$ & DP \\
\hline VN/LA/2019-ASF3 & Ben Luc/Long An & September, 2019 & $\mathrm{~S}$ & DP \\
\hline VN/TG/2020-ASF1 & Tien Giang & July, 2020 & $\mathrm{~S}, \mathrm{Sp}, \mathrm{K}, \mathrm{L}, \mathrm{LN}$ & DP \\
\hline $\mathrm{VN} / \mathrm{VL} / 2019-\mathrm{ASF} 1$ & Binh Minh/Vinh Long & August, 2019 & $\mathrm{~S}$ & DP \\
\hline
\end{tabular}

DP: Domestic pig; CP: Convalescent pig; WB: whole blood; S: serum, LN: lymph node; Sp: pleen; L: lung; K: kidney; WB: whole blood. 
Genomic DNA Purification System (Promega, USA). PCR amplification for the genomic characterization of ASFV was performed to amplify the variable 3 '-end of the B646L gene, whole gene E183L encoding the p54 protein, and the CP204L (p30) gene using primers that showed in Table 1.

All PCR amplifications were performed using kit MyTaq TM HS Mix, 2x (Bioline, USA). Reactions contained $12 \mu \mathrm{L}$ MyTaq TM HS Mix, $5 \mu \mathrm{L}$ DNA, $1 \mu \mathrm{L}$ of $10 \mu \mathrm{M}$ Forward primer, $1 \mu \mathrm{L}$ of 10 $\mu \mathrm{M}$ Reverse primer, and $6 \mu \mathrm{L}$ free-DNA water in a total reaction volume of $25 \mu \mathrm{L}$. The positive control DNA was given by Veterinary Hospital Laboratory of Nong Lam University (Vietnam). DNA extracts were substituted by nuclease free water in negative control reaction. Thermocycling condition for PCR detection of ASFV included a 10 min initial denaturation step of $95^{\circ} \mathrm{C}$, followed by 40 cycles of $15 \mathrm{sec}$ at $95^{\circ} \mathrm{C}, 30 \mathrm{sec}$ at $62^{\circ} \mathrm{C}$, and $30 \mathrm{sec}$ at $72^{\circ} \mathrm{C}$ with a 5 -min elongation step at $72^{\circ} \mathrm{C}$. Thermocycling condition for amplification of the p72, p54, and p30 genes, the initial denaturation at $95^{\circ} \mathrm{C}$ for $5 \mathrm{~min}$, followed by 40 of 30 sec at $95^{\circ} \mathrm{C}, 30 \mathrm{sec}$ at $55^{\circ} \mathrm{C}$, and $1 \mathrm{~min}$ at $72^{\circ} \mathrm{C}$, and a final elongation at $72^{\circ} \mathrm{C}$ for $10 \mathrm{~min}$. Afterward, PCR products were mixed with GelRed nucleic acid stain (Merck, Germany) and electrophoresed in a $1 \%$ agarose gel electrophoresis (Invitrogen, Thermo Fisher Scientific, USA) using $1 \mathrm{~Kb}$ Plus ladder (Invitrogen, Thermo Fisher Scientific, USA) to indicate the sizes of amplification products.

\subsection{Genetic sequence and analysis}

The PCR products of 3 gene regions (p72, p54, and p30) were purified using the TopPURER PCR/GEL DNA PURIFICATION kit (ABT, Vietnam) and were sent to sequencing laboratory (Macrogen, Korea). Both sequences from the forward strand and the reverse complement sequences were manually overlapped to obtain a single sequence. The nucleotide sequences of the B646L, E183L and CP204L genes of the collected ASFV strains were compared with previous Vietnamese strains and with other sequences published available in GenBank (NCBI) (Table 3). The nucleotide sequences of three defined genes obtained were aligned using the CLUSTAL W package and phylogenetic analyses were conducted according to the maximum likelihood approach with a bootstrap value of 1000 in the MEGA X software (https://www.megasoftware.net).

\section{Results}

\subsection{Confirmation of ASF using PCR}

The 20 pigs included sows, fattening pigs, and nursing pigs that showed specifically pathological and clinical signs of ASF, including fever (41 - $42^{\circ} \mathrm{C}$ ), loss of appetite, vomiting, skin hemorrhages, bloody discharge from the nose, and joint swelling. PCR revealed a band size of $257 \mathrm{bp}$, hence 20 pigs tested positive for ASF viral DNA (gel not shown).

\subsection{Nucleotide and amino acid sequence ana- lyis}

\subsubsection{Sequence alignment}

Nucleotide and amino acid sequences of partial p72, full-length p54, and p30 of the 20 strains shared $100 \%$ sequence identity with each other. They shared $98.63 \%$ - 100\% nucleotide and amino acid identity with the partial p72, full-length p54, and p30 sequences of genotype II reference isolates. The amino acid sequence alignment revealed that 20 strains shared $96.42 \%-100 \%$ p72 sequence identity, $100 \%$ p 54 sequence identity, and $99.42 \%$ - $100 \%$ p30 sequence identity within p72 genotype II. Interestingly, nucleotide and amino acid sequences of partial p72, fulllength p54, and p30 of CN201801 (MH735140) and Jilin/2018 (MK189456) ASFV strains from China shared $100 \%$ sequence identity with 20 strains in this study (Figure 2).

\subsubsection{Phylogenetic analysis}

P72 phylogenetic tree: The p72 genotyping $\mathrm{PCR}$ results indicated a band size of $478 \mathrm{bp}$ from all the samples using primers P72U/P72D (gel not shown). Phylogenetic analysis and comparison of these sequences to other isolates of known genotypes identified the 20 sequences belonging to B646L genotype II as shown in Figure 2A.

P54 phylogenetic tree: A band size of $676 \mathrm{bp}$ was amplified using primers PPA722/PPA89 (gel not shown). Analysis of whole-length p54 sequences confirmed that the circulating virus belongs to genotype II (Figure 2B).

P30 phylogenetic tree: PCR amplification of CP204L gene from each of 20 field strains pro- 


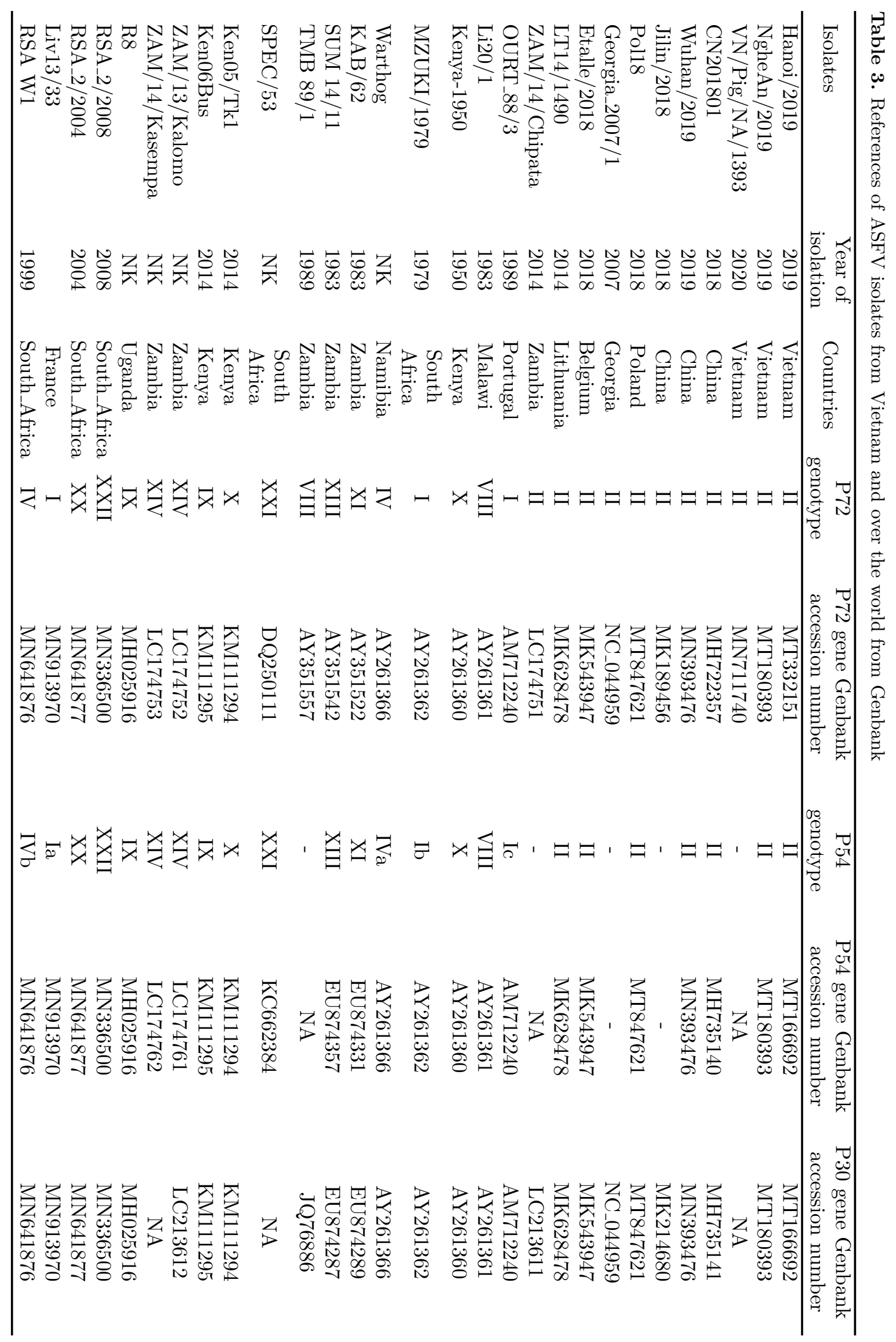



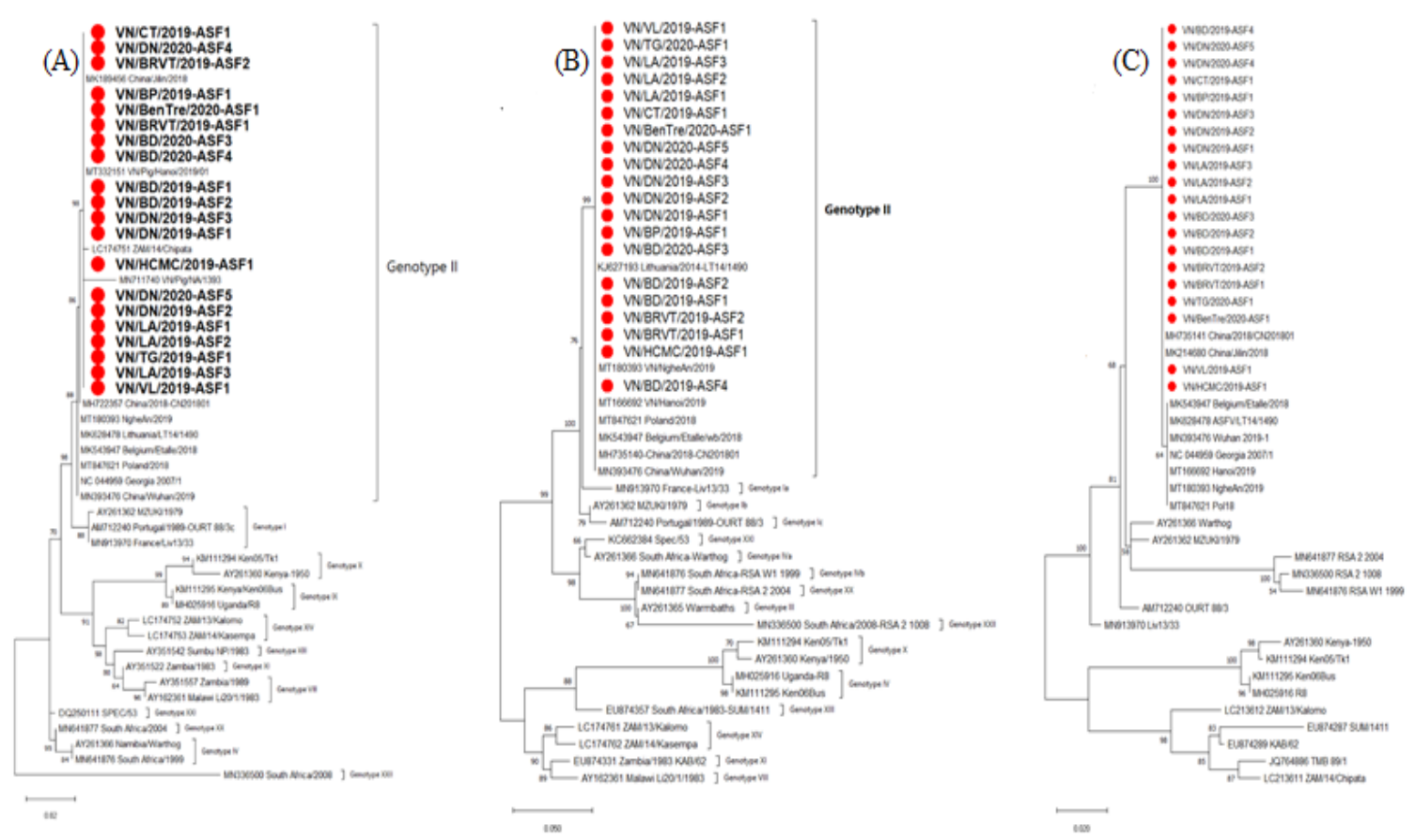

Figure 2. ASFV phylogenetic trees based on nucleotide sequences of genes encoding p72-p54-p30. (A) P72 genotype (B) P54 sub-group within p72 genotype, (C) P30 phylogenetic trees. The maximum likelihood approach was used for construction of phylogenetic trees in MEGA X software (https://www.megasoftware.net/). Numbers along branches indicate bootstrap values > 50\% (1000 replicates). The red circles are ASFVs from this study. Scale bars indicate nucleotide substitutions per site.

duced a 521 bp band (gel not shown). All ASFVs collected from the 2019 - 2020 outbreaks in Southern Vietnam were indistinguishable in the p30 phylogeny. Except for one virus (ZAM14/Chipata, accession no. LC213611), all p72 genotype II ASFVs belonged to the same clade (Figure 2C).

\section{Discussion}

Phylogenetic analysis based on nucleotide sequences of the $\mathrm{C}$-terminal of the $\mathrm{B} 646 \mathrm{~L}$ gene (p72), full-length E183L (p54) gene showed that all 20 Vietnamese ASFV field strains belonged to genotype II. The other analysis of p30 phylogeny showed that this genomic region could differentiate among closely related viruses (Simulundu et al., 2017). The findings are in contrast to those of a previous study in which p30 sequences obtained from ASFV collected from 10 different provinces over two years showed remarkable genetic stability and so could not obtain a finer level of discrimination among closely related viruses using this genomic region. The idea that illegal transportation of pork and pork products, triggering the outbreak in Southern Vietnam seems to support from this genetic analysis, which showed that the virus in this study was very similar in the comparison based on any of three selected gene fragments (B646L, E183L, and CP204L) to ASFVs which caused outbreaks in China during 2018 (CN201801 and Jilin/2018).

On the other hand, the analysis and comparison of the three independent regions of ASFV gene sequences in this study and other reports in Vietnam showed high stability of the ASFV genome (Le et al., 2019; Mai et al., 2021). However, the finding conflicted with the previous study in which p72 sequences obtained from ASFV collected from Nghe An province showed the presence of some nucleotide point substitution mutations (Tran et al., 2020). In general, the mutation rate of DNA viruses is lower than RNA viruses and ranges between $10^{-8}$ to $10^{-6}$ substitutions per nucleotide per cell infection (Sanjuan et al., 2010). Mowever, double-stranded DNA's evolutionary rate is difficult to estimate (Firth et al., 2010). The accurate proofreading of DNA polymerase and virus-encoded base excision DNA 
repair system results in a low mutation rate in ASFV DNA. Our results may be rational to the previous description that ASFV is very stable and shows a very low mutation rate, which leads to low genetic variability in affected regions (Dixon et al., 2020). Interestingly, the virus collected from apparently convalescent pigs in a survey following this study had presented $100 \%$ of identity in the 3 ASFV genome regions of the 2019 - 2020 ASFV strains which induced an acute form of the infection for the 20 pigs. It could be assumed that after the first introduction of the disease in an area, increased numbers of subacute and subclinical infections could happen over time, and that mortality rates decrease. In such circumstances, the clinical manifestations are more variable, and recognition of the disease becomes problematic in the field, emphasizing the need for implementation of appropriate surveillance programs to control the disease. This study provides the phylogenetic information about ASFV strains circulating in Southern areas of Vietnam during 2019 - 2020, which will be useful for ASF control program in Vietnam and neighboring countries.

Vietnam shares a cross-border with China, and illegal transport of pigs and pig products frequently occurs in the border provinces of both countries (Kreindel et al., 2018). On the other hand, Vietnam imports pork and other pork products from different European countries, such as Poland, Russia. The exact route of the introduction of ASFV into Vietnam remains unknown. According to recent molecular studies, some different ASFV strains circulate in China (Ge et al., 2018; 2019). These strains may represent multiple introductions of ASFV into China or intra-epidemic genome variation caused by a genetic mutation. To trace the source and extend the knowledge of ASFV evolution and epidemiology in Vietnam, we analyzed nucleotide and amino acid sequences of three defined regions of the genome B646L, E183L, and CP204L from the tested ASFV. Because all nucleotide and amino acid sequences for each genome region from all pigs in various cases obtained from Vietnam were identical, this study concluded that the ASF outbreaks in Vietnam and the surrounding areas were probably due to a single introduction of the virus. The genetic analysis results also reflected the rapid spread of pathogens within six months, spread to 63 provinces throughout the country and from a single source after entering Vietnam. ASFV is a pathogen that spread slowly in nature or under strict supervision. A nationwide outbreak of ASF indicated that the control of the epidemic in Vietnam was quite loose and less stringent. Vietnam has many small and household-scale farms, typically poor biosecurity, outdated facilities, limited breeding techniques and low awareness of veterinary regulations, which were significant contributors to the introduction, spread, and circulation of the disease. Besides, a lot of slaughterhouses and fresh meat markets are located close to the livestock sector, increasing the difficulty of disease control in Vietnam.

\section{Conclusions}

The results revealed that ASFV circulating in Southern Vietnam during 2019 - 2020 outbreaks belong to genotype II. The combination of molecular data and epidemiologic findings have confirmed that the ASFVs detected in Southern regions of Vietnam most probably originated or showed the same genetic relatedness to ASFVs detected in Northern Vietnam during 2019 and China in 2018. Analysis of the three independent genes of ASFV in this study and previous studies in Vietnam showed high stability of ASFV genome.

\section{Acknowledgments}

The study funded by the Scientific Research Fund of Nong Lam University, Ho Chi Minh City, Vietnam which was coded CS-SV20-CNTY-01.

\section{References}

Aguero, M., Fernandez, J., Romero, L., Sanchez Mascaraque, C., Arias, M., \& Sanchez-Vizcaino, J. M. (2004). Highly sensitive pcr assay for routine diagnosis of African swine fever virus in clinical samples. Journal of Clinical Microbiology 41(9), 4431-4434.

Bastos, A. D. S., Penrith, M. L., Crucière, C., Edrich, J. L., Hutchings, G., Roger, F., Couacy-Hymann, E., \& Thomson, G. R. (2003). Genotyping field strains of African swine fever virus by partial p72 gene characterisation. Archives of Virology 148(4), 693-706.

Dixon, L. K., Stahl, K., Jori, F., Vial, L., \& Pfeiffer, D. U. (2020). African swine fever epidemiology and control. Annual Review of Animal Biosciences 8, 221-246.

FAO (Food and Agriculture Organization). (2020). ASF situation in Asia update. Retrieved March 5, 2020, from http://www.fao.org/ag/againfo/programmes/en/ empres/ASF/2020/Situation_update_2020_03_05.html. 
Firth, C., Kitchen, A., Shapiro, B., Suchard, M.A., Holmes, E.C., \& Rambaut, A. (2010). Using timestructured data to estimate evolutionary rates of double-stranded dna viruses. Molecular Biology and Evolution 27(9), 2038-2051.

Gallardo, C., Fernández-Pinero, J., \& Arias, M. (2019). African swine fever (ASF) diagnosis, an essential tool in the epidemiological investigation. Virus Research 271, 197676.

Gallardo, C., Mwaengo, D. M., Macharia, J. M., Arias, M., Taracha, E. A., Soler, A., Okoth, E., Martín, E., Kasiti, J., \& Bishop, R. P. (2008). Enhanced discrimination of African swine fever virus isolates through nucleotide sequencing of the p54, p72, and pb602l (cvr) genes. Virus Genes 38(1), 85-95.

Gallardo, C., Reis, A. L., Kalema-Zikusoka, G., Malta, J., Soler, A., Blanco, E., Parkhouse, R. M. E., \& Leitao, A. (2009). Recombinant antigen targets for serodiagnosis of African swine fever. Clinical and Vaccine Immunology 16(7), 1012-1020.

Gallardo, C., Soler, A., Nieto, R., Cano, C., Pelayo, V., Sánchez, M. A., Pridotkas, G., Fernandez-Pinero, J., Briones, V., \& Arias, M. (2017). Experimental infection of domestic pigs with African swine fever virus lithuania 2014 genotype ii field isolate. Transboundary and Emerging Diseases 64(1), 300-304.

Ge, S., Li, J., Fan, X., Liu, F., Li, L., Wang, Q., Ren, W., Bao, J., Liu, C., Wang, H., Liu, Y., Zhang, Y., $\mathrm{Xu}, \mathrm{T} ., \mathrm{Wu}, \mathrm{X}$., \& Wang, Z. (2018). Molecular characterization of African swine fever virus, china, 2018. Emerging Infectious Diseases 24(11), 2131-2133.

Ge, S., Liu, Y., Li, L., Wang, Q., Li, J., Ren, W., Liu, C., Bao, J., Wu, X., \& Wang, Z. (2019). An extra insertion of tandem repeat sequence in African swine fever virus, china, 2019. Virus Genes 55(6), 843-847.

Kreindel, S. , Pittiglio, C., Pinto, J., Lockhart, C., Calistri, P., Lubroth, J., \& Correa, M. (2018). African swine fever threatens people's republic of China - a rapid risk assessment of ASF introduction. Rome, Italy: FAO.

Le, P. V., Jeong, G. D., Yoon, S. W., Kwon, H. M., Trinh, N. T. B., Nguyen, L. T., Bui, N. T. T., Oh, J., Kim, B. J., Cheong, M. K., Nguyen, T. V., Bae, E., Vu, H., T. T., Yeom, M., Na, W., \& Song, D. (2019). Outbreak of African swine fever, Vietnam, 2019. Emerging Infectious Diseases 25(7), 1433-1435.

Mai, A. N. T., Vu, D. X., Nguyen, H. T. T., Nguyen, T. V., Trinh, N. T. B., Kim, J. Y., Kim, H. J., Cho, K. H., Nguyen, L. T., Bui, N. T. T., Jeong, G. D., Yoon, S. W., Truong, T., Ambagala, A., Song, D., \& Le, P. V. (2021). Molecular profle of African swine fever virus (ASFV) circulating in Vietnam during 2019-2020 outbreaks. Archives of Virology 166(3), 885-890.
Nix, R. J., Gallardo, C., Hutchings, G., Blanco, E., \& Dixon, L. K. (2006). Molecular epidemiology of African swine fever virus studied by analysis of four variable genome regions. Archives of Virology 151(12), 24752494.

OIE (World Organisation for Animal Health). (2019). African swine fever situation. Retrieved January, 2021, from https://www.oie.int/fileadmin/Home/eng/Health standards/tahm/3.08.01_ASF.pdf?fbclid=IwAR0xd3m Fl-ultXzS-GmCqjLdJVzgV6a13SrJI-sWi84jwKuFRfqHenOsg.

OIE (World Organisation for Animal Health). (2018). African swine fever in Hungary. Retrieved February, 2021, from https://www.oie.int/app/uploads/2021/ 03/report-47-global-situation-asf.pdf.

Quembo, C. J., Jori, F., Vosloo, W., \& Heath, L. (2018). Genetic characterization of African swine fever virus isolates from soft ticks at the wildlife/domestic interface in mozambique and identification of a novel genotype. Transboundary and Emerging Diseases 65(2), 420-431.

Rowlands, R. J., Michaud, V., Heath, L., Hutchings, G., Oura, C., Vosloo, W., Dwarka, R., Onashvili, T., Albina, E., \& Dixon, L. K. (2008). African swine fever virus isolate, Georgia, 2007. Emerging Infectious Diseases 14(12), 1870-1874.

Sanjuan, R., Nebot, M. R., Chirico, N., Mansky, L. M., \& Belshaw, R. (2010). Viral mutation rates. Journal of Virology 84(19), 9733-9748.

Simulundu, E., Lubaba, C. H., Van Heerden, J., Kajihara, M., Mataa, L., Chambaro, H. M., Sinkala, Y., Munjita, S. M., Munang'andu, H. M., Nalubamba, K. S., Samui, K., Pandey, G. S., Takada, A., \& Mweene, A. S. (2017). The epidemiology of African swine fever in "nonendemic" regions of Zambia (1989-2015): Implications for disease prevention and control. Viruses 9(9), 236.

Tran, T. H. T., Truong, D. A., Ly, V. D., Vu, H. T., Hoang, T. V., Nguyen, C. T., Chu, N. T., Nguyen, H. T., Pham, T. N., Nguyen, T., Yersin, A. G., \& Dang, V. H. (2020). Genetic characterisation of African swine fever virus in outbreaks in ha nam province, red river delta region of vietnam, and activity of antimicrobial products against virus infection in contaminated feed. Journal of Veterinary Research 64(2), 207-213. 